\title{
ИСПОЛЬЗОВАНИЕ ИНСТРУМЕНТОВ ПРОЕКТНО-ПРОЦЕССНОГО ПОДХОДА В УПРАВЛЕНИИ ЗАТРАТАМИ НА ПРЕДПРИЯТИЯХ МАЛОГО И СРЕДНЕГО БИЗНЕСА В УСЛОВИЯХ УСИЛИВАЮЩЕЙСЯ РЫНОЧНОЙ КОНКУРЕНЦИИ
}

\author{
(C) 2020 Жабин Александр Петрович \\ доктор экономических наук, профессор \\ Самарский государственный экономический университет, Россия, Самара \\ E-mail: apzhabin@yandex.ru \\ (c) 2020 Волкодавова Елена Викторовна \\ доктор экономических наук, профессор \\ Самарский государственный экономический университет, Россия, Самара \\ E-mail:vev.sseu@gmail.com
}

В статье содержатся результаты исследования практики реагирования руководителей предприятий малого и среднего бизнеса (в дальнейшем - МСП) на периодически проявляющиеся в мировой и российской экономике кризисные явления.

Показывается, что подавляющая часть МСП в период экономических кризисов и обострения конкурентной борьбы в качестве главного средства реагирования использует сокращение затрат на производство продукции. В качестве эффективного средства обеспечения конкурентоспособности авторами статьи предлагается использование инструментов проектно-процессного подхода в управлении затратами. Раскрывается суть проектно-процессного подхода, система его инструментов, преимущества и возможные ограничения в применении, обусловленные особенностями малого и среднего бизнеса.

Ключевые слова: проектно-процессное управление, управление затратами, малые и средние предприятия, экономические кризисы, конкурентоспособность

Введение. Предприятия малого и среднего бизнеса являются важной составной частью народнохозяйственной экосистемы каждой страны. Все государства мира теми или иными способами поддерживают малый и средний бизнес, рассматривая его не только как важную отрасль экономики, но и как базу обеспечения социальной устойчивости общества. В Российской Федерации в силу исторических особенностей ее развития эта поддержка особенно актуальна. Именно поэтому в основополагающем документе, определяющем приоритеты в развитии страны - Указе Президента России «О национальных целях и стратегических задачах развития Российской Федерации на период до 2024 года» от 7 мая 2018 г. № 204 [1] - была предусмотрена разработка специального национального проекта «Малое и среднее предпринимательство и поддержка индивидуальной предпринимательской инициативы».

В разработанном и реализуемом в настоящее время национальном проекте предусмотрены масштабные меры государственной поддержки малого и среднего бизнеса, в том числе такие как упрощение доступа к льготному финансированию, совершенствование системы закупок, осуществляемых крупнейшими заказчиками у субъектов малого и среднего предпринимательства, создание системы акселерации и цифровой платформы, ориентированной на поддержку производственной и сбытовой деятельности, создание системы поддержки экспортеров, являющихся субъектами малого и среднего предпринимательства, и ряд других. Эти меры существенно дополнили ранее принятые и законодательно закрепленные меры поддержки [2]. Однако, несмотря на меры, принимаемые государством, развитие малого и среднего предпринимательства идет неровно, испытывая сильное влияние периодически возникающих кризисных ситуаций. Как свидетельствуют официальные статистические данные, численность малых и средних предприятий и занятых в этом сегменте экономики в 2016-2018 годах росла. Но уже с начала 2018 г. наметилась обратная тенденция. Особенно было заметно снижение активности предприятий и их численности в 2019м г. после увеличения НДС до $20 \%$. 
Динамика количества предприятий малого и среднего бизнеса по итогам 2017-2018 гг. по статистическим данным представлена в таблице 1 [3].

Количество малых предприятий по итогам 2018 г. снизилось на 94634 ед. $(-3,44 \%)$, в том числе микропредприятий на 76228 ед. (-3,05\%). В 2018 г. отмечен рост средних предприятий на 373 ед. (+2,8\%) относительно 2017 г. Министерство финансов отмечает, что говорить о сокращении доли МСП не стоит, т.к. объем их выручки за 2018 г. вырос на 25\%. К числу причин, повлиявших на сокращение количества субъектов МСП, А. Силуанов отнес укрупнение малого бизнеса и успехи Федеральной налоговой службы ФНС в борьбе с фирмами-однодневками [4].

Действительно, рост выручки наблюдается. Но необходимо отметить, что положительная динамика выручки, о которой идет речь, частично обусловлена ростом НДС с $18 \%$ до $20 \%$, инфляцией, переходом предприятий крупного бизнеса в статус среднего бизнеса, а среднего в статус малого, в связи с ухудшением показателей деятельности.

Анализ статистических данных за 20172018 гг. показал, что снижение числа МСП и численности работающих на них наблюдается практически по всем видам деятельности, оно достаточно равномерное [5].

Если анализировать факторы, по причине влияния которых за период 2017-18 г.г. ограничивается инвестиционная деятельность малых предприятий, то ключевым фактором деструктивного влияния является неопределенность экономической среды (см. табл.2) [6].

В условиях нового финансового кризиса, вызванного падением цены на нефть по причине выхода России из сделки «ОПЕК+» [7] и последствиями пандемии коронавируса COVID-19 [8], ухудшение положений предприятий малого и среднего бизнеса неизбежно в связи с нарастанием неопределенности бизнес-среды.

Безусловно, правительство РФ разработало действенные меры по поддержке предприятий малого и среднего бизнеса, такие как: отсрочка арендных платежей, отсрочка по налоговым платежам и страховым взносам и многие другие. Несмотря на существенную действенность этих мер поддержки, по сравнению с предприятиями крупного бизнеса, МСП в наименьшей степени защищены от влияния внешних факторов.

В данное время, эти гибкие, инновационные, проявляющие предпринимательскую инициативу базовые звенья рыночной экономики, вынуждены искать новые организационноэкономические резервы своей предпринима-

Таблица 1. Динамика количества предприятий малого и среднего бизнеса по итогам 2017-2018 гт.

\begin{tabular}{|c|c|c|c|}
\hline \multirow{2}{*}{ Годы } & \multicolumn{2}{|c|}{ Малые предприятия } & \multirow{2}{*}{ Средние предприятия, ед } \\
\cline { 2 - 3 } & Всего, ед. & $\begin{array}{c}\text { в том числе микропред- } \\
\text { приятия, ед. }\end{array}$ & 13309 \\
\hline 2017 & 2754577 & 2497879 & 13682 \\
\hline 2018 & 2659943 & 2421651 & 2,80 \\
\hline Динамика в \% & $-3,44$ & $-3,05$ & \\
\hline
\end{tabular}

Таблица 2. Распределение малых предприятий по оценке факторов, ограничивающих инвестиционную деятельность (в процентах от общего числа организаций)

\begin{tabular}{|l|c|c|}
\hline \multicolumn{1}{|c|}{ Фактор } & 2017 г. & 2018 г. \\
\hline Недостаточный спрос на продукцию & 23 & 27 \\
\hline $\begin{array}{l}\text { Несовершенная нормативно-правовая база, регулирующая } \\
\text { инвестиционные процессы }\end{array}$ & 21 & 48 \\
\hline $\begin{array}{l}\text { Сложный механизм получения кредитов для реализации } \\
\text { инвестиционных проектов }\end{array}$ & 35 & 47 \\
\hline Инвестиционные риски & 31 & 54 \\
\hline Высокий процент коммерческого кредита & 41 & 58 \\
\hline Высокий уровень инфляции в стране & 38 & 49 \\
\hline Недостаток собственных финансовых средств & 44 & 61 \\
\hline Неопределенность экономической ситуации в стране & 42 & \\
\hline
\end{tabular}

1) Без микропредприятий. 
тельской деятельности. Эти резервы менеджеры предприятий малого и среднего бизнеса могут выявить в процессе оптимизации издержек при реструктуризации существующей бизнесмодели, адаптируя ее параметры к изменившимся условиям внешней среды.

Малые и средние предприятия вынуждены прибегать к кардинальным мерам по снижению своих издержек, но особый положительный эффект, в условиях нестабильного спроса и его падения, достигается при условии снижения постоянных расходов. Чем ниже их уровень, тем меньше рисков получения убытков в случае снижения спроса и выше запас финансовой прочности. Это актуально для всех предприятий, но для малого и среднего бизнеса это особенно актуально, так как доля постоянных расходов в общем объеме затрат у МСП существенно выше.

Малые и средние предприятия, как правило, в меньшей степени применяют аутсорсинг; практически не используют инструменты временного пользования основными средствами; не имеют возможности применять системы оплаты труда, максимально ориентированные на результаты деятельности предприятия в целом. Такие компании без разработки грамотной системы оплаты труда не могут гарантировать сотрудникам стабильный уровень заработной платы в ввиду колебаний спроса на их продукцию (услуги, работы) и вынуждены устанавливать фиксированный ее размер, удовлетворяющий персонал, чтобы снизить текучесть кадров. Эти и другие факторы обусловливают высокую долю постоянных расходов в структуре затрат малых и средних предприятий.

Нестабильность внешней среды не позволяет оптимизировать и удельные переменные расходы. Для малых и средних предприятий они не являются постоянной величиной, какими они являются на крупных предприятиях с массовым или крупносерийным производством.

МСП особенно нуждаются в грамотной и гибкой системе управления затратами. Этим обусловлена актуальность настоящего исследования.

Проектно-процессный подход к управлению затратами на малых и средних предприятиях. В последние десятилетия развиваются проектный и процессный подходы к управлению хозяйствующим субъектом. С точки зрения стратегического управления их назначение различно, но такой комплексный, системный под- хода, как раз и позволит получить оптимальный вариант реструктуризации элементов существующей бизнес-модели.

Проектный подход к управлению предприятием позволяет использовать факторы внешней среды, эффективно проводить политику диверсификации и повышать результативность отдельных направлений деятельности, конкретных заказов посредством выделения отдельной команды и назначения руководителя, ответственных за выполнение проекта. Проектный подход позволяет выделить ключевые блоки бизнес-модели и зоны ответственности при управлении ими. Диверсификация деятельности в последние годы выступает основным инструментов снижения рисков на малых и средних предприятиях.

Процессный подход нацелен на выделение процессов (функций) на предприятии, непосредственно связанных с производством конкретного вида продукции (работ, услуг), и повышение эффективности деятельности предприятия преимущественно за счет внутренних факторов. В основу такого подходу легли методы ABC-costing и функционально-стоимостной анализ (далее ФСА). Роль процессного подхода при реструктуризации бизнес-модели аналогична задачам функционально-стоимостного анализа, но в рамках действующих и планируемых бизнес-процессов.

По нашему мнению, эти подходы не противоречат друг другу, удачно дополняют методологический потенциал инструментария предпринимателя при анализе существующей бизнес-модели и ее реструктуризации с целью выхода из кризисной ситуации. Они могут быть успешно применены, т.к. проектный подход к управлению отвечает на вопрос «Что делать, чтобы получить максимальную прибыль?», а процессный - «Как делать?».

Процессный подход применительно к управлению затратами заключается, прежде всего, в грамотном распределении процессов и отдельных функций к конкретным видам продукции (работ, услуг) по принципу причастности, исключении излишних процессов и неэффективных функций посредством построения, анализа и постоянного совершенствования цепочки создания ценности, оптимизации расходов, связанных с производством и реализацией продукции (работ, услуг) [9]. Проектно-процессный подход отличим тем, что применяется в конкретных 
проектах. Это, в свою очередь, упрощает применение процессного подхода за счет локализации множества задач, в том числе по выделению процессов и определению их причастности к производству конкретного вида продукции (работ, услуг).

Совместное применение подходов к управлению затратами на малых и средних предприятиях имеет ряд преимуществ. Если проект представляется в виде процессов (основных, вспомогательных, управленческих, процессов развития) с отображением связей между ними, это позволяет:

- построить и усовершенствовать организационную структуру управления проектами;

- оптимизировать информационный поток и документооборот;

- определить владельцев, исполнителей процессов, тем самым сформировать команду проекта и грамотно распределить ответственность за показатели проекта;

- обосновать систему оплаты труда, КРI, тем самым оптимизировать размер постоянных затрат;

- выявить процессы, которые могут быть реализованы аутсорсинговыми или сторонними компаниями, что также позволяет сократить долю постоянных расходов.

Инструменты процессного управления в СУП, в частности ФСА, АВС-costing, стандарты ISO, цепочка создания ценности, на основе которой могут быть выделены процессы, позволяют:

- оптимизировать поток ресурсов, необходимых для реализации проекта, их запасы, стоимость;

- исключить неэффективные и излишние операции (функции), наиболее затратные процессы;

- определить «узкие» участки, увеличивающие продолжительность и стоимость проекта;

- точнее спрогнозировать размер потребности в оборотном капитале во времени;

- выявить резервы сокращения расходов.

Проектно-процессный подход к управлению затратами является гибким и высоко эффективным инструментом в современных условиях нестабильности внешней среды. Он отвечает потребностям малых и средних предприятий.

В отличии от крупных предприятий, где организационная структура, как правило, является функциональной, дивизионной или смешанной, и выступает основным сдерживающим фак- тором для внедрения проектно-процессного управления, на малых и средних предприятиях его существенно проще реализовать. Тем не менее, существуют свои особенности его реализации.

Особенности применения проектнопроцессного подхода к управлению затратами на малых и средних предприятиях. Проектно-процессный подход реализуем не на всех малых и средних предприятиях. Для его применения требуется относительное постоянство осуществляемых видов деятельности предприятием или наличие относительно крупных и продолжительных по времени заказов, которые могут быть положены в основу формирования проекта, а производимая продукция (работы, услуги) - в качестве выхода процессов.

При реализации проектного подхода на малых и средних предприятиях многие члены команды выполняют функции, обеспечивающие работу нескользких проектов на предприятии, и несут ответственность за их результаты. Это, как правило, прежде всего относится к отделам бухгалтерского учета, снабжения, юристам и т.д. На крупных предприятиях в большинстве подразделений имеется возможность четко разграничить обязанности сотрудников, закрепив их за конкретным проектом.

Задействование одних и тех же лиц в нескольких проектах, реализуемых на малых и средних предприятиях, затрудняет распределение расходов различных подразделений по проектам, а далее на единицу продукции (работы, услуги). В таких ситуациях в основу распределения косвенных расходов может лечь трудоемкость работ, обусловленных каждым реализуемым проектом, пропорционально которой распределяются расходы подразделений, задействованных в нескольких проектах.

Алгоритм внедрения проектно-процессного подхода к управлению затратами на малых и средних предприятиях представлен на рис. 1

Прежде чем начать внедрять проектнопроцессный подход по управлению затратами на предприятии, необходимо идентифицировать маркетинговую стратегию. На малых и средних предприятиях, как правило, не проводится качественная ее разработка.

На первом этапе крайне важно определить:

- кто клиент предприятия?

- в чем потребность клиента? 


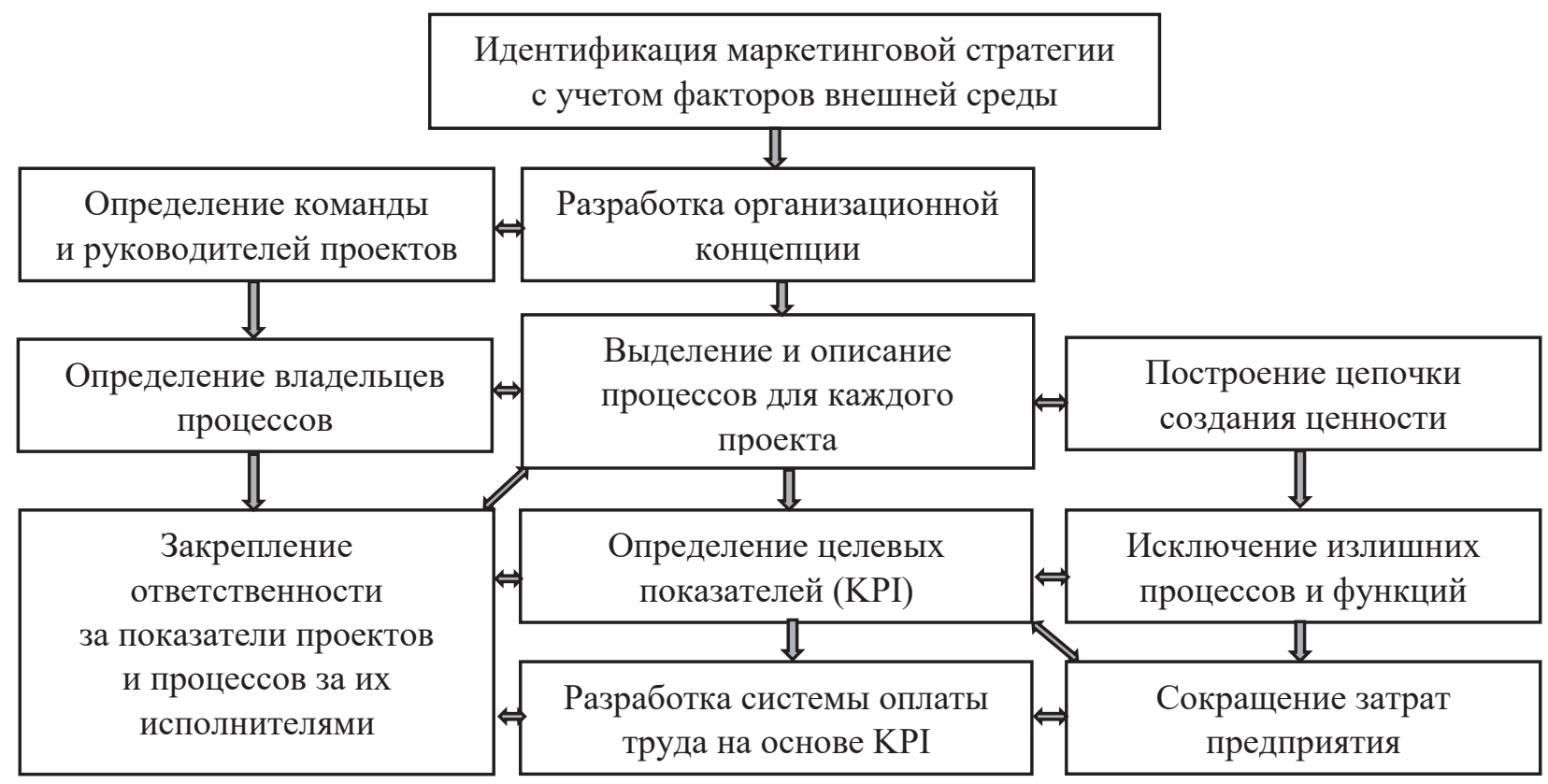

Puc. 1. Алгоритм внедрения проектно-процессного подхода к управлению затратами на малых и средних предприятиях

- в чем конкурентные преимущества продукции (работ, услуг) предприятия?

Второй вопрос позволяет определить основные направления деятельности и ключевые продукты предприятия. Основные направления деятельности в большинстве случаях можно представить в качестве проектов, если такой подход управления уместен, а ключевые продукты - в качестве выходов процессов.

Важным этапом внедрения проектнопроцессного подхода к управлению затратами на предприятии является разработка организационной концепции. Проектно-процессный подход к управлению затратами требует перестройки структуры управления, но в отличии от крупных предприятий, на малых и средних этот этап является менее болезненным. Необходимо обозначить и описать бизнес-процессы верхнего уровня для каждого проекта и предприятия в целом. Параллельно определяются команды и руководители проектов.

Далее следует выделить и описать процессы для каждого проекта, где это целесообразно и возможно, на основе цепочки создания ценности; определить владельцев процессов; определить ключевые показатели для проектов в целом, а где это возможно, попроцессно; документально закрепить ответственность за показатели за их исполнителями.
Параллельно анализируется и совершенствуется цепочка создания ценности с целью повышения эффективности деятельности предприятия, сокращения расходов посредством исключения излишних процессов, операций, функций и потерь.

На основе разработанных KPI, с учетом закрепленной ответственности за руководителями и исполнителями процессов и проектов разрабатывается система оплаты труда с целью оптимизация затрат предприятия и повышения его эффективности.

Выводы. Проектно-процессный подход к управлению затратами на малых и средних предприятиях в условиях нестабильной экономической среды является актуальным инструментом реструктуризации бизнес-модели. Менеджменту малых и средних предприятий необходимо учитывать, что его применение ограничено множественными факторами, в первую очередь, видами деятельности, осуществляемыми предприятиями, их количество и постоянство.

Сложности его внедрения на МСП заключаются прежде всего в ограниченности кадровых ресурсов и одновременном задействовании сотрудников в нескольких проектах, что затрудняет процессы разработки КРI, распределения косвенных расходов по проектам и далее на еди- 
ницу продукции.

Представленный в работе алгоритм позволяет подойти к внедрению проектно-процессного подхода к управлению затратами на малых и средних предприятиях последовательно.
Этот подход позволяет гибко реагировать на изменения спроса на рынке, оптимизировать размер постоянных расходы, сократить общие затраты предприятия, распределить их на единицу выпускаемой продукции работы, (услугу).

\section{Библиографический список}

1 Указ Президента РФ от 7 мая 2018 г. № 204 «О национальных целях и стратегических задачах развития Российской Федерации на период до 2024 года».

2 Федеральный закон от 24 июля 2007 г. № 209-Ф3 «О развитии малого и среднего предпринимательства в России».

3 Малое и среднее предпринимательство в России. 2019: Стат.сб./ М 19 Росстат.- М., 2019-87 с. [Электронный ресурс].URL: https://www.gks.ru/folder/210/document/13223

4 Министерство финансов Российской Федерации [Электронный ресурc]. URL: https://www.minfin.ru/ru/

5 Малое и среднее предпринимательство в России. 2019: Стат.сб./ М 19 Росстат.- М., 2019-87 с.

6 Министерство финансов Российской Федерации [Электронный ресурc]. URL: https://www.minfin.ru/ru/

7 Место рождения цен. Почему Россия вышла из нефтяной сделки ОПЕК+ / Российская газета [Электронный pecypc]. URL: https://rg.ru/2020/03/09/pochemu-rossiia-vyshla-iz-neftianoj-sdelki-opek.html

8 Эксперты рассказали о последствиях коронавируса для мировой экономики / Российская газета [Электронный ресурс]. URL: https://rg.ru/2020/03/09/pochemu-rossiia-vyshla-iz-neftianoj-sdelki-opek.html

9 Наугольнова И.А. Основы процессного подхода к управлению затратами на промышленных предприятиях // Экономика, предпринимательство и право.- 2020. - Том 10. - № 3.- doi: 10.18334/epp.10.3.100746. 